\title{
Applyling Taiwan Aboriginal culture's feature to product Design
}

\author{
Yi-Hsien Lin /1st Author \\ Department of Creative Product Design and Management \\ Far East University \\ Tainan, Taiwan \\ Email: yisam0915@yahoo.com.tw (Corresponding Author)
}

\author{
Heng-Yau Pan/ 2nd Author \\ Department of Leisure and Sports Management \\ Far East University \\ Tainan, Taiwan
}

\begin{abstract}
Jenn-Yang Lin/ 3nd Author
Department of Industrial Design

National Cheng Kung University

Tainan, Taiwan
\end{abstract}

\begin{abstract}
Product design is usually based on life experience and national culture today. Taiwan aboriginal culture has unique and special individual feature element. Taiwan aboriginal cultures may represent a significant part of Taiwan culture. Some product design utilized Taiwan aboriginal culture artistic elements. Designers absorb spirit of life style and culture perspective from Taiwan aboriginal culture to design products with Taiwan aboriginal graphic symbol elements.
\end{abstract}

The study used elemental characteristics analytical method. The researcher abstracted culture element from Taiwan aboriginal artistic and used Kawakita Jiromothed Semantic differential life style analysis follow by product perceptual evaluation to design and develop new Taiwan aboriginal style products.

key words: aboriginal, culture element feature, life style, product develop design

\section{INTRODUCTION}

The Intention of aboriginal is that the first resident people or origin Taiwan local people in Taiwan. The definition of aboriginal is that people inhabiting or existing in a land from the earliest times before the arrival of colonists. The first resident people in Taiwan can be called Taiwan aboriginal.

Taiwan Ministry of the Interior divided Taiwan aboriginal into nine tribes after World War II. In 2002, Taiwan Ministry of the Interior added two tribes in Taiwan aboriginal tribes. They are Ami, Atayal, Bunun, Paiwan, Puyuma, Rukai, Saisiyat, Yami, Tsou, Ge Ma Lan, and Taroko. In addition, the Pingpu people also represented that people was assimilated from Han nationality for a long time. Every aboriginal tribe has different artistic character and individual cultural features in Taiwan aboriginal living environment. The study was going to do cultural and creative product development base on Taiwan aboriginal artistic and life elements.

\section{BACKGROUND OF REVIEW}

\section{Taiwan aboriginal artistic}

Taiwan aboriginal artistic may be represented as the first local Taiwan artistic. Taiwan aboriginal artistic presents not only various feature but present unquiet distinctive national characteristics. Taiwan aboriginal artistic combine every tribe live experience and history memory. Taiwan aboriginal art works present faith, history, society, and culture identity. Although some Taiwan aboriginal culture societies lost today, they still keep strong vitality and colorful artistic styles.

Carving and embroidery are the quintessence of the Taiwan aboriginal artistic. There are many special art performances in Taiwan aboriginal artistic. Paiwan, Yami and Ge Ma Lan are good at carving skill. Paiwan, Rukai, Puyuma all good at art. Social class system helps them create colorful art works. Their art works present simple style and full of vitality. Their sculpture and painting shows sincere and pure.

Men work outside while women work within the house is Taiwan aboriginal life style. Men do hunting, woman do weaving. When woman do weaving, many patterns were be used on their cloth. They use irregular weaving skill and no beam type complex weaving skill to make clothes. Each art work and each clothe is unique. In addition, they also put shell and pearl on the clothes to make decoration. We call it kaaha

It is nature for human to trace beauty. Taiwan aboriginal artistic has some influence to human beings. In the modern society, it is good for people to keep Taiwan aboriginal art works to inherited human history culture treasures.

\section{Inherited design element}

The ideas of Taiwan aboriginal artistic creation is based on Taiwan aboriginal cultural and creative elements. Designers do Taiwan aboriginal artistic product design should follow by these concepts and make design with fashion modern skills clothes in Atayal language. 
today. Designers should use Kamsei Adjectives to design patterns and design product with Taiwan aboriginal artistic elements. Processing of Human Visual information was divided into stages [2].

\section{Kansei Adjectives}

There are two stages in the processing of human visual information gaining [2]. In the first stage, human would scan hall visual picture or image to gain pattern and form quickly. Then, people may establish image cognition of the object quickly. Kansei adjectives played significant role to describe the consumer's feelings, because it is needed for designers to understand the relationship between consumer and product [4].

\section{Kawakita Jiro Method}

$\mathrm{KJ}$ method is a tool that could solve problem by using text and images to simply complicated problems [5]. KJ method could help researchers think brainstorming and work together. The study could use KJ method for grouping the Kansei adjectives and employed to pick the representative samples [3].

\section{Method of Semantic Differential}

SD method means Method of semantic differential. It was created by Osgood. Osgood was a psychologist in American. SD method could exam the difference toward a variety.

\section{Kansei Evaluation}

Product design has perceptual and rational thinking especially in the design process. Product design should follow by consumers' behavior. Therefore, it is need for designer to use Kansei Evaluation during design process. Mituo Nagamachi showed that the purpose of doing Kansei engineering was to understand consumers' thinking to develop new products [4]. By following Kansei Evaluation and Kansei Adjectives analyze, designers could gain datas and design product that feed the need of customers.

\section{Cluster Analysis}

Cluster analysis (CA) is a good way to classify and simplify the large amount of data into several groups with same features by counting the distance in the data space [1]. CA was very common for designer to do consumer segmentation in $\mathrm{KE}$ [6]. Moreover, CA also can be used to screen out Kansei adjectives and representative samples [5]. Therefore, the study implanted CA for grouping forms.

\section{Life Style}

Food

Paiwan tribe eat taro as their stable food. They do farming and some hunting or fishing in daily life. There are three living circle areas in Paiwan social living environment. The central first circle society is farming sacrifice group. The main members are noble. The second circle society is hunting area. The third circle society is fishing group. Traditional Paiwan food includes millet dumplings. Millet dumplings made from millet, pork, taro and wrap with month peach leaves. Bamboo rice, stone $\mathrm{BBQ}$, betel nut and rice wine are Paiwan traditional dessert for wedding and festivals.

\section{Cloth}

Paiwan cloth represents individual social status. Each cloth has its' unique style. Paiwan noble clothes are gorgeous. There are ancestral images, head pattern, agkistrodon acutus pattern and sun pattern on Paiwan noble clothes. Civilian clothes designed with simple color with some decorations. Cloth system includes formal style, sport style, working style and daily style. Colorful decoration is the best portrayal in Paiwan clothes system.

Embroidery is one of the special artistic works in fabric design. There are cross stitch, Satin embroidery, quilting stitch skills. Tailor use red, orange, yellow, green, blue, black and white colors to do pattern design and to show individual artistic performance. Embroidery clothes are hand make decorate with glass beads. Paiwan people are famous at embroidery. Paiwan tribe and Rukai tribe are all good at embroidery.

\section{Living}

In geography speaking, there are many stones and rocks around Paiwan tribe villages. Therefore, Paiwan people used slate to build their houses. People call it stone house. Paiwan people imitate Scales of Agkistrodon to build their stone house. The stone house has living room, bed room, kitchen and main space. Paiwan people used to set up a statue in front of their stone hose. The statue could represent house owners' social status.

1. Front door lintel is very low. People should bend over to go through the door.

2. Indoor floor was made by soil. The house was divided into two spaces. Front space is bedroom. Back space is kitchen and storage room.

3. Bed is arranged in the right or left corner in the bedroom. There is a pillar in the center of the room. There are naked men and naked women sculpture on the pillar. It is the most sacred area in the bedroom.

4. A terrace was set up in front of chief house. A terrace is a place that chief could make order to all tribe residents.

5. Many houses built pig house near inner wall of their house.

6. In front of the house, there is a vestibule design with flat square stone and some stone chairs seating.

\section{MethodologIES}

Data Collection:

Kansei adjectives and Representative samples

Questionnaire:

SD and Evaluations toward samples

Analysis:

Kansei adjectives and CA 
Purpose of the study

1. The purpose of the study was construction Taiwan aboriginal culture characteristics element.

2. The researcher utilized Taiwan aboriginal culture element to design modern products. Taiwan aboriginal cultures have various characteristic. They include art, festivals, life styles, and other aboriginal culture elements. After Aggregated data and information, the designer can design new modern products with Paiwan culture. By using aboriginal culture elements with modern perspective to design new products will make close connection with every people. In addition, people will learn some Taiwan aboriginal culture and traditional artistic by using the new products with Taiwan aboriginal culture and creativity style.

3. The characteristic of Taiwan aboriginal artistic element pattern

Today, people live in modern society. It is good for people to inherited traditional culture by using Taiwan aboriginal element to design products. It addition, it is also good for designer to use Taiwan aboriginal culture element and patterns as design system to make a modern product design.

The study absorbs Taiwan aboriginal pattern design element follow by people's vision.

Design element based on Taiwan aboriginal pattern characteristic.

Paiwan tribe culture presents more colorful artistic performance than the other twelve Taiwan aboriginal tribes. Paiwan art works include Clay pot, Sculpture, Glass beads, embroidery and bronze knife. These art works have their potential develop characteristic. The study focused on Paiwan arts and crafts. The study transferred Paiwan culture characteristic into modern product design. The following graph showed the analysis of Paiwan culture characteristic.

TABLE I. Paiwan culture characteristic analysis

\begin{tabular}{|c|c|c|c|}
\hline Art type & meaning & Symbolic & use \\
\hline $\begin{array}{l}\text { Ciljimuk } \\
\text { Clay pot }\end{array}$ & precious & $\begin{array}{c}\text { Noble status, } \\
\text { marriage }\end{array}$ & $\begin{array}{l}\text { Gift, bride } \\
\text { price }\end{array}$ \\
\hline Sculpture & Social status & $\begin{array}{c}\text { Noble, } \\
\text { Ancestral } \\
\text { spirits }\end{array}$ & $\begin{array}{c}\text { More } \\
\text { decoration } \\
\text { function than } \\
\text { practical }\end{array}$ \\
\hline $\begin{array}{l}\text { Glass } \\
\text { beads }\end{array}$ & Honorable & $\begin{array}{c}\text { Special } \\
\text { status and } \\
\text { honorable }\end{array}$ & $\begin{array}{l}\text { Heirloom and } \\
\text { bride price }\end{array}$ \\
\hline embroidery & decoration & no & cloth \\
\hline $\begin{array}{l}\text { bronze } \\
\text { knife }\end{array}$ & adult & $\begin{array}{l}\text { Adult male, } \\
\text { warrior }\end{array}$ & $\begin{array}{c}\text { Festival, } \\
\text { hunting }\end{array}$ \\
\hline
\end{tabular}

\section{Ciljimuk}

Ciljimuk is Clay pot in Paiwan language. The function of ciljimuk was drinking water pot. There is a bamboo scoop in the top of the ciljimuk. When the water ran out, the bamboo scoop will fall down to the bottom of the pot. Ciljimuk only can be used during harvest festival. Only chief, warriors and hunters allow drinking ciljimuk water (Jiang Bin, 1940). In the early age, Paiwan people made clay pot with black color only. The function of Ciljimuk was not only for storage water but for Divination. Moreover, Paiwan noble also give Ciljimuk as a gift to their important people or other noble members. The surface of Ciljimuk was decorated with Engraved. There are three types of Paiwan Ciljimuk. They are male Ciljimuk, female Ciljimuk and yin yang Ciljimuk. Today, designers may make Paiwan Ciljimuk have any form of styles.

\section{Sculpture}

The pattern of Paiwan sculpture is Agkistrodon. The Paiwan people believed that Agkistrodon is their ancestor. Agkistrodon and eagle feather represent the authority of Paiwan chief. Paiwan sculptures include column sculpture, daily necessities product sculpture, wall panels sculpture, lintel and beam sculpture. Paiwan designers have some different engraving style. Therefore, Paiwan designers were divided into some groups based on their engraving styles. However, all Paiwan designers use to use Agkistrodon as their main symbolic. Paiwan designer used to make ancestor portrait on the column sculpture. People can easy learn and recognize different social level based on different wearing style form the sculpture. Paiwan designers should follow traditional style to do sculpture. On the other hand, the different between wall panels sculpture and column carving sculpture is that wall panels sculpture is shallow carving instead of deep carving. Moreover, wall panels sculpture has color and realistic carving style.

\section{Glass beads}

Glass beads have many different colors and patterns. These represent people social status. Glass beads products include watch necklace and jewelry products.

The origin of Paiwan glass beads was difficult to research. Some researcher thank that the Spanish people, the Dutch people or the British brought it with Expeditionary Force. They used glass beads exchange food, water and other treasure goods from Island residents. They called glass beads trading beads. Paiwan people used to string silverware with glass beads as necklace. Every Paiwan glass bead has its own myth story. The treasure Paiwan glass beads necklace are only belong to chief, noble, taboo, discipline, trade and sacrifice. Paiwan glass beads wearing styles include female single string pectoral, three to five string pectoral and nine to thirteen string pectoral. The Paiwan string glass beads wearing style is female only. The Paiwan people think that wearing glass beads has Spiritual power protection from their gods.

\section{Bronze knife}

Bronze knife also means supernatural stick. Paiwan people respect bronze knife because they believed god's soul lived in the bronze knife. However, Paiwan warrior did not use Bronze knife as their weapon. When Paiwan warrior went out for fight, they hold a Religious ritual. They put some meat into Acacia tree. After ritual, they carry the meat and go fighting. They believed their god will protect them and victory will 
stand with them. There was an old saying that the bronze knife would sing when Paiwan warrior win a war. An old story said that human was born from a stone. In order to protect human, god gave human Bronze knife. Today, there are few Bronze knives in Paiwan tribe. Paiwan parents will prepare a bronze knife when they have a new born male baby. Bronze knives represent man power and authority in Paiwan society.

\section{APPLYING TAIWAN ABORIGINAL ARTISTIC ELEMENT INTO MODERN PRODUCT DESIGN}

Taiwan Aboriginal product design utilize feature

Agkistrodon pattern extraction

It is easy to recognize that there are triangle patterns on the skin of Agkistrodon. Therefore, form of triangle, diamond, square and mesh graphs could be used to represent Agkistrodon pattern elements. In the early time, only noble have qualifications to use Agkistrodon pattern. In addition, it is common to found that head pattern, porprait pattern, deer pattern and potted pattern are also can be found with Agkistrodon pattern in any Paiwan sculptures or life products.

Graph I Agkistrodon pattern elements

\begin{tabular}{|c|c|c|}
\hline Original picture & Main element & Element1 \\
\hline sumes & 6 & \\
\hline
\end{tabular}

Sun pattern extraction

It is easy to found that circle pattern can represent as a pattern of sun. Some detail patterns such as diamond and triangle also can spirit of sun.

Graph II sun pattern elements

\begin{tabular}{|c|c|c|c|}
\hline $\begin{array}{c}\text { Original } \\
\text { picture }\end{array}$ & $\begin{array}{c}\text { Main } \\
\text { element }\end{array}$ & Element 1 & Element 2 \\
\hline 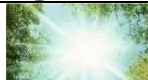 & & & \\
\hline
\end{tabular}

When some Paiwan pattern elements were abstracted, students of design faculty design some products by using Paiwan pattern elements especially Agkistrodon pattern.

Graph III Taiwan Aboriginal pattern element product design utilize

\begin{tabular}{|c|c|c|c|c|}
\hline $\begin{array}{c}\text { Original } \\
\text { picture }\end{array}$ & Design 1 & Design 2 & Design 3 & Design 4 \\
\hline & & & \\
\hline
\end{tabular}

Graph IV Taiwan Aboriginal pattern design utilize in pottery

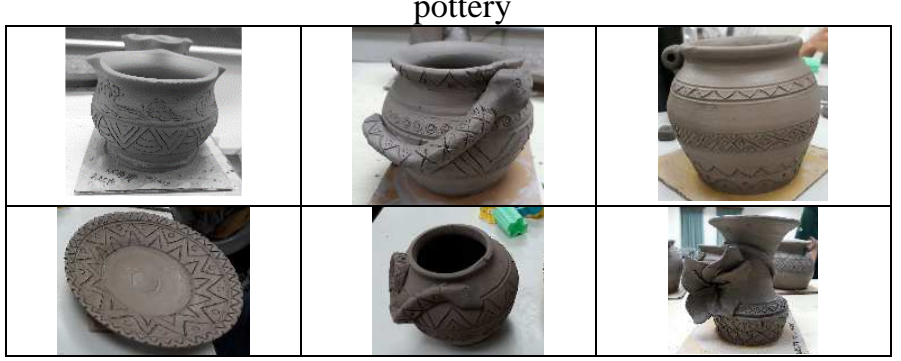

Description of Paiwan style design:

1. Agkistrodon pattern style is serious triangle patterns. The pattern is usually used in fabric product design.

2. Son pattern style is circle radial pattern form. The pattern is usually used in daily necessities products.

3. Taiwan aboriginal male Ciljimuk and female Ciljimuk usually designed with Agkistrodon pattern.

\section{SUMMARY}

Taiwan aboriginal culture feature has variety patterns. Agkistrodon pattern is one of the most popular and famous pattern in Taiwan aboriginal product design. Ciljimuk, sculpture, glass beads, embroidery, bronze knife all has different characteristic. The study used Taiwan aboriginal patterns element transfer to modern features for daily necessities products design. These may bring some fun for our daily life.

\section{References}

[1] Anderberg, M.R. (1973). Cluster Analysis for Applications. New York, Academic Press.

[2] Baxter, M. (1995). Product Design: Practical Methods for the Systematic Development of New Products, CRC Press.

[3] Hsiao, K.A.\& Chen, .L. (2006). Fundamental dimensions of affective responses to product forms. International Journal of Industrial Ergoonmics, 36 (6): 553-564

[4] Nagamachi, M. (1995). Kansei engineering: a new ergonomic consumeroriented technology for product development. International Journal of Industrial Ergonomics, 15 (1): 3-11.

[5] Wang, T. H. (20002). A study on the influence of the features of a bike's frame. National Chang-Kung University, Taiwan.

[6] Yang, C.C., Sun, C.C., Lin, P. J. \& Tsai, C.C. (2011). A general frame work for Kansei engineering system. International Journal of Digital Content Technology and its Applications, 5(10): 173-180. 